\title{
ATENÇÃO ODONTOLÓGICA EM PACIENTES HOSPITALIZADOS E PORTADORES DE DOENÇAS INFECTOCONTAGIOSAS
}

Lesões bucais e em outros tecidos e órgãos em indivíduos portadores da infecção HIV/AIDS são variáveis e mostram diferenças em relação a sua manifestação clínica e severidade. Este estudo teve por objetivo determinar a prevalência das lesões bucais e peribucais em pacientes adultos portadores de HIV/AIDS internados no Hospital Oswaldo Cruz, Curitiba/PR. Um total de 450 pacientes adultos (293 homens e 157 mulheres com média de idade de 40 anos) foi submetido a exame clínico intrabucal. Aproximadamente $93 \%$ dos pacientes $(n=420)$ apresentaram algum tipo de lesão bucal. A língua saburrosa $(46,89 \%)$ e cáries $(37,56 \%)$ foram as entidades mais comuns, seguidas por candidoses $(33,33 \%)$ e doença periodontal $(30,22 \%)$. Outras lesões observadas foram leucoplasia pilosa, hiperpigmentação de melanina, estomatite ulcerosa (aftosa), herpes simples, ceratose friccional, queilite angular, língua despapilada, hiperemia traumática e granuloma piogênico. Candidíases e doença periodontal foram as mais comuns manifestações clínicas oro-regionais, associadas à infecção pelo HIV, encontradas. Lesões bucais são características comuns em pacientes imunocomprometidos, principalmente naqueles indivíduos que não fazem uso controlado da terapia antirretroviral. $\mathrm{O}$ manejo destas entidades é fundamental para melhorar a qualidade de vida dos indivíduos infectados.

Palavras-chave: Síndrome de Imunodeficiência Adquirida; Candidíase; Mucosa Bucal. 